\title{
Analysis of the Spatiotemporal Land-Use/Land-Cover Change and its Driving Forces in Fuxian Lake Watershed, 1974 to 2014
}

\author{
Shi-Hua Li ${ }^{1,2 *}$, Bao-Xuan Jin ${ }^{2}$, Jun-Song Zhou ${ }^{2}$, \\ Jin-Liang Wang ${ }^{1}$, Shuang-Yun Peng ${ }^{1}$ \\ ${ }^{1}$ College of Tourism and Geographic Sciences, Yunnan Normal University, Kunming, 650500, China \\ ${ }^{2}$ Yunnan Provincial Geomatics Centre, Kunming, 650034, China
}

Received: 1 July 2016

Accepted: 8 October 2016

\begin{abstract}
Land-use/land-cover change (LUCC) is an important issue of research into global change. To identify the spatiotemporal change and the driving mechanism of land use at the regional scale is of great significance to environmental preservation and economic development in the whole locality. In order to analyze the spatiotemporal change of land cover in Fuxian Lake watershed for the last four decades, our paper extracted the information of land use and land cover in the area using the method of combining supervised classification with visual interpretation. The process of extraction referred to a total of 10 time series remotesensing images (namely the 1974, 1977, 1987, 1990, 1996, 2000, 2006, 2009, 2012, and 2014 phases) as the main data source, and drew on the achievement data from the China Geography Census as an ancillary source. Accordingly, we obtained the spatiotemporal characteristics of the land-cover type change in Fuxian Lake watershed for the last 40 years. Finally, based on the socioeconomic data in the locality, using principal component analysis and multiple regression analysis, this paper analyzed the driving forces of LUCC in the watershed to acquire the major driving force factors, and built up a corresponding multiple linear regression model. The same kind of model was established for the local cultivated land and its driving force factors. The result shows that:

1) In terms of changing trends, along with the increasing human activities in the socioeconomic domain of the catchment, the last four decades has seen a mounting local number of gardens, building regions (districts), roads, structures, artificial piling and digging of land, as well as wastelands and bare surface. As a contrast, there has been a decreasing trend for cultivated land, woodland, grassland, and water for the same term.

2) The variation degree of land cover was higher during the period 1990-96 and 2000-06, and was the lowest in 1974-77.
\end{abstract}

*e-mail: jinbx163@163.com 
3) During 1974-77, 1987-2000, 2006-14, and 1974-2014, there was a noticeable discrepancy between the converted areas of various land-use types, which was higher for woodland, grassland, and arable land, and was lower for water by comparison.

4) The cultivated area in Fuxian Lake watershed was positively correlated with such factors as overall population, natural population growth rate, the production value of the primary industry, the production value of the tertiary industry, industrial production value, GDP, fiscal expenditure, living expenditure per capita, and annual average temperature. It was negatively correlated with some other factors, including agricultural population, agricultural production value, rural income per capita, total retail sales of consumer goods, grain total output, the per unit area yield of grain, the amount of fertilizer used in agriculture, the amount of pesticide used in agriculture, and annual average precipitation.

Keywords: Fuxian lake watershed, land-use/land-cover change, spatiotemporal change, driving mechanism

\section{Introduction}

Land serves as the fundamental natural resource and material basis for human beings to survive and develop [1]. LUCC is a crucial part of and one of the major causes behind global environmental change [2-4]. Research into the process, pattern, and driving force of land use is deemed to effectively reveal the law of spatiotemporal change of land use [2-3]. Researchers at home and abroad have conducted numerous studies on the dynamic change and driving forces of land use. Scholars in North America, represented by B.L. Turner [3], used to model land-use change and land process management by framing them in comparative case studies for analysis at the macro level, aiming to quantitatively study the relationship between global-scale land-use change and environmental change [5-6], while European scholars mostly take land use as a whole system to simulate land-use change in different time and space. Welfare analysis is undertaken in researching socioeconomic driving factors of land use [7]. For Japanese scholars, in order to quantitatively study the process of regional land-use change, they mainly use the analysis methods that combine economic models with quantitative models as a means to select explanatory variables that act as a basis for the follow-up simulation of land-use change and its policy environment, where KSIM simulation method or the like is employed [8]; as a comparison, RS technology and GIS technology are mostly used by domestic scholars to study land-use change and its driving factors in research regions selected with prominent contradiction between people and land and where economic development is rapid. The land-use level change model [9], the driving force diagnosis model [10], and the land-use structure prediction model [11], for example, are separately combined with mathematical statistical analysis methods as a means for such studies.

Given that LUCC in various regions has different contributions and responses to global change, research into LUCC at the regional scale is concentrated in "mostconcerned areas," "vulnerable districts," and "key regions" [11-13]. Using high-resolution images and combing socioeconomic factors to analyze the LUCC mechanism in the lake watershed has been not reported.
Yunnan plateau area is one of the Chinese areas with centralized distribution of lakes. The nine plateau lake catchment in Yunnan covers nearly $8,000 \mathrm{~km}^{2}$, equal to $2 \%$ of Yunnan's land area. Population around the catchment accounts for $9.3 \%$ of the total population in Yunnan, and GDP around 34\% of the provincial GDP. The sustainable development of nine lake areas is vital to the social and economic development of Yunnan [14]. Fuxian Lake is one of the nine plateau lakes in Yunnan, and is also the second deepest lake in China. Its area and water storage rank it in eighth and third places across the country, respectively. Its special geological location, strong water supply capacity, and high tourism value win for it the great fame of "plateau pearls" in the central region of Yunnan Province. It is not only an important resource guarantee of socially and economically sustainable development in central Yunnan, but also a strategic water resource for the development of the pan-pearl river delta. It also provides drinking water for Zhujiang Rivers and southwestern China [15]. However, with climate warming and the increase of human economic activities, Fuxian lake levels have faced more and more serious threats. Therefore, monitoring the current land use in Fuxian Lake watershed can provide significant geo-information and a scientific basis for comprehensive statistics and analysis of climate change forecast, ecological assessment, and macro regulation analysis. Meanwhile, the monitoring results can serve as governmental and official decision support on the protection of Fuxian Lake and its resource development and management.

\section{Material and Methods}

\section{Study Area}

Fuxian Lake $\left(24^{\circ} 21^{\prime} 38^{\prime \prime}-24^{\circ} 38^{\prime} 00^{\prime \prime} \mathrm{N}, 102^{\circ} 49^{\prime} 12^{\prime \prime}\right.$ $\sim 102^{\circ} 57^{\prime} 26^{\prime \prime} \mathrm{E}$; Fig. 1) is located in Chengjiang, Jiangchuan, and Huaning counties of Yuxi city, central Yunnan. It lies in the center of the Central Yunnan basin, and is $60 \mathrm{~km}$ southeast of Kunming. Fuxian is the largest deep freshwater lake by volume in China, the largest lake near the source of the Pearl River, and a member of the 


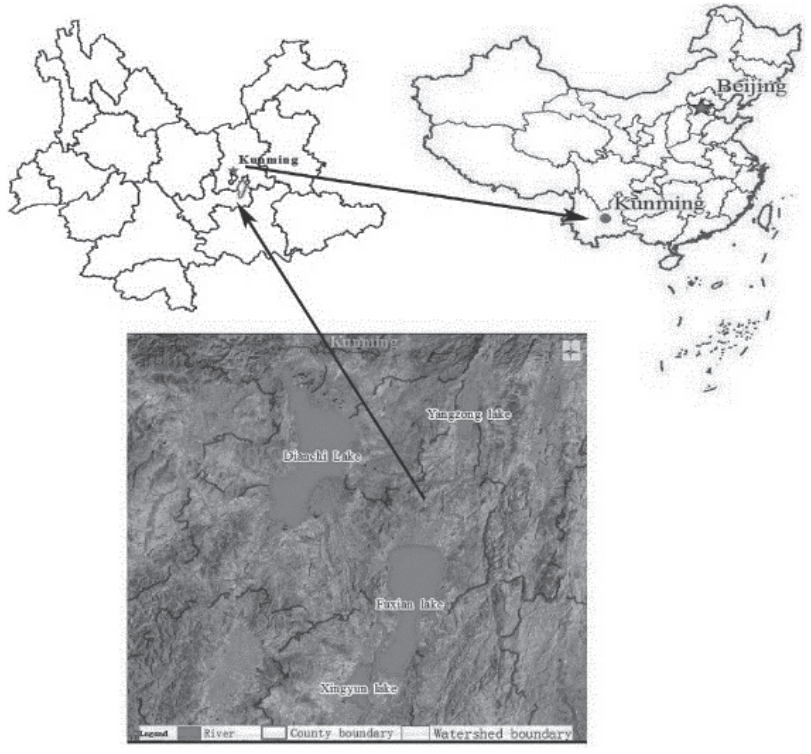

Fig. 1. location of Fuxian Lake catchment.

Nanpanjiang River system. The water quality of Fuxian is Class I, which means that it is counted as one of the natural lakes with best water quality in China. Predominant in the catchment is secondary vegetation such as tussocks, boscage, and coniferous forest. The area has a population of around 160,300. Its agricultural economy lies mainly in crop production, with the staple food crops of rice, corn, and wheat, and a cash crop of flue-cured tobacco and rapeseed oil. In terms of industry, this area gives priority to phosphorous chemical industry (the pillar industry), building materials, food processing, and aquatic products. The land-use type in the catchment is all along forests and water, which has changed to a certain degree in recent years due to the phenomena of reclamation of land from lakes and forests, overdevelopment of tourism resources, and diversified functional land for construction.

\section{Data Source}

The research mainly adopted medium-to-highresolution remote sensing images processed by MSS, TM, ETM+, QuickBird, and WorldView-2. Among the 10 time series image data, the medium-resolution ones were all downloaded from the United States Geological Survey (glovis.usgs.gov). QuickBird images and WorldView-2 images were accessed from either video vendors or relative industry departments. For effective analysis of and comparison between remote sensing image data of landuse change in the watershed, image data from December to March (dry season) with favorable comparability was chosen as its primary data source (Table 1). 1:10000DLG data and 1:250000DLG data acted as main geoinformation data for Fuxian Lake catchment, while socioeconomic data was obtained from the Bureau of Statistics of Yuxi City. The demarcation of the Fuxian catchment was provided by the Fuxian Lake Administration to Yuxi City. The geography census achievement data for the targeted catchment came from the leading group office to the national geography census in Yunnan Province. The achievement data for the watershed in the first and second national land surveys came from documents issued by the Department of Land Resources of Yunnan Province.

\section{Data Processing}

1:250,000 DLG data was referred to by MSS images, TM images, and ETM+ images, while QuickBird images in 2009 and WorldView-2 images in 2014 were obtained from the achievement data of the first national land survey (DOM) in Yunnan. Supported by ERDAS imaging, the paper corrected roads, river intersections and feature points with prominent terrains from image to image, with no less than 25 control points for each image. The second order polynomial model was used for geometric precision correction on the eight time series remote sensing images.

Table 1. Remote sensing image data for Fuxian Lake catchment.

\begin{tabular}{|c|c|c|c|c|c|}
\hline Satellite sensor & Time phase & $\begin{array}{c}\text { Spatial resolution } \\
(\mathrm{m})\end{array}$ & Path & Row & Source \\
\hline Landsat MSS & $1977-01-05$ & 79 & 139 & 43 & glovis.usgs.gov \\
\hline Landsat TM & $1987-01-07$ & 30 & 129 & 44 & glovis.usgs.gov \\
\hline Landsat TM & $1989-01-20$ & 30 & 129 & 43 & glovis.usgs.gov \\
\hline Landsat TM & $1996-01-16$ & 30 & 130 & 44 & glovis.usgs.gov \\
\hline LandsatETM+ & $2000-02-20$ & 30 & 129 & 44 & glovis.usgs.gov \\
\hline QuickBird & $2006-03-09$ & 0.61 & - & - & $\begin{array}{c}\text { From achievement data of the second national land } \\
\text { survey }\end{array}$ \\
\hline QuickBird & $2009-12-18$ & 0.61 & - & - & From satellite agents \\
\hline WorldView-2 & $2012-01-29$ & 0.5 & - & - & $\begin{array}{c}\text { From achievement data of the first national land } \\
\text { survey }\end{array}$ \\
\hline WorldView-2 & $2014-01-26$ & 0.5 & - & - & From satellite agents \\
\hline
\end{tabular}


Geometric errors were restricted within one pixel. China Geodetic Coordinate System 2000 was used for spatial reference, and $6^{\circ}$ Gauss-Kruger projection with a central meridian of $105^{\circ}$ acted as the projection type.

The Xi'an Geodetic Coordinate System 1980 was used as the image coordinate system of the 2006 achievement data in the second national land survey (DOM) in Yunnan, and coordinate conversion was required accordingly. Thus, the parameters for conversion from Xi'an Geodetic Coordinate System 1980 to China Geodetic Coordinate System 2000, which was provided by the Geomatics Center of Yunnan Province, was used to transform the coordinates of the original achievement data into the corresponding ones in the China Geodetic Coordinate System 2000.

The tier-one classification system in contents and indicators for the first national geography census was used for the proposed image classification system that covered the whole area of Fuxian catchment [14], where the land-cover classification data were divided into 10 types: cultivated land, woodland, grassland, gardens, building region (district), roads, structures, artificial piling and digging land, wastelands and bare surface, and water. ERDAS Imagine was applied to classify land-cover types of the targeted watershed.

\section{Methods}

\section{Extraction of Local LUCC Data}

Although it underwent precise rectification by the same reference source, the remote sensing images selected could possibly have inconsistent precision due to the characteristics of multiple time phases and diversified resolutions. Therefore, when land-cover data was extracted, the rectified precision, if any, would bring changes to non-changing surface features. To address this problem, manual interpretation was conducted on the landcover achievements (LCAs) from the geography census in the catchment in 2012, for which the LCAs as the background data were overlapped with the highresolution images in 2006, 2009, and 2014. In this way, those regions whose boundaries and attributes were detected to have varied with time were updated to the newest data, while the unchanged regions remained the same. Moreover, the LCAs were compared with the achievement data in the first and the second national land survey in the catchment. Finally, we obtained the land-use type maps during different periods and the statistic table for areas of various land-cover types, as shown in Figs 2-3 and Table 2, respectively. In this way, the extracted data can be proven accurate, and the monitoring result of the conversion of LUCC can be ensured to be reliable.

\section{Methods for Temporal LUCC}

Various land-use categories that are interfered with diversified natural and human factors have different changing rates, whose regional discrepancy can be represented by the land-use dynamic degree model [6].

The single dynamic degree of land use refers to the change of the number of a certain land-use type within certain time limits in the research area. It acts as the quantitative description of the velocity of change for such land-use types for a certain duration in the targeted area. As a comparison, the synthetic dynamic degree of land use represents the overall dynamics of land use in a certain area [15-17]:

$$
\begin{aligned}
K=\frac{U_{\mathrm{b}}-U_{\mathrm{a}}}{U_{\mathrm{a}}} & * \frac{1}{T} * 100 \% \\
& * \text { MERGEFORMAT }
\end{aligned}
$$

...where $\mathrm{K}$ denotes the dynamic degree of a land-use type during the research period, which reflects the actual magnitude of the land-use type change in a land-use/landcover area; $\mathrm{U}_{\mathrm{a}}$ and $\mathrm{U}_{\mathrm{b}}$ represent the number of a land-use types at the start and end of the research, respectively; and $\mathrm{T}$ is the research period.

$$
L C=\left(\frac{\sum_{i=1}^{\mathrm{n}} \Delta L U_{i \rightarrow j}}{2 \sum_{i=1}^{n} L U_{i}}\right) * \frac{1}{T} * 100 \%
$$

I* MERGEFORMAT (2-2)

...where LC represents the synthetic land-use dynamic degree in the research area, $\mathrm{LU}_{\mathrm{i}}$ denotes the area of the i-type land use at the start of the monitoring period, $\Delta \mathrm{LU}_{\mathrm{i} \rightarrow \mathrm{j}}$ is the absolute value of the area converted from the i-type land use to any land-use types other than the i-type during the monitoring period, and $\mathrm{T}$ denotes the duration of the monitoring period.

\section{Methods for Spatial LUCC}

A conversion matrix is a main quantitative approach for studying the number and direction of different converted land-use types. It can specifically reflect the structural characteristics of land-use change and the corresponding conversion directions. The mathematical formula of the conversion matrix is expressed as [18]:

$$
P=\left[\begin{array}{cccc}
p_{11} & p_{12} & \cdots & p_{1 n} \\
p_{21} & p_{22} & \cdots & p_{2 n} \\
\vdots & \vdots & \vdots & \vdots \\
p_{n 1} & p_{n 2} & \cdots & p_{n n}
\end{array}\right]
$$

...where $p$ denotes area, $n$ represents the number of landuse types, and $i$ and $j$ in $\mathrm{p}_{i j}$ separately denote the land-use landscape types at the start and end of the research. 

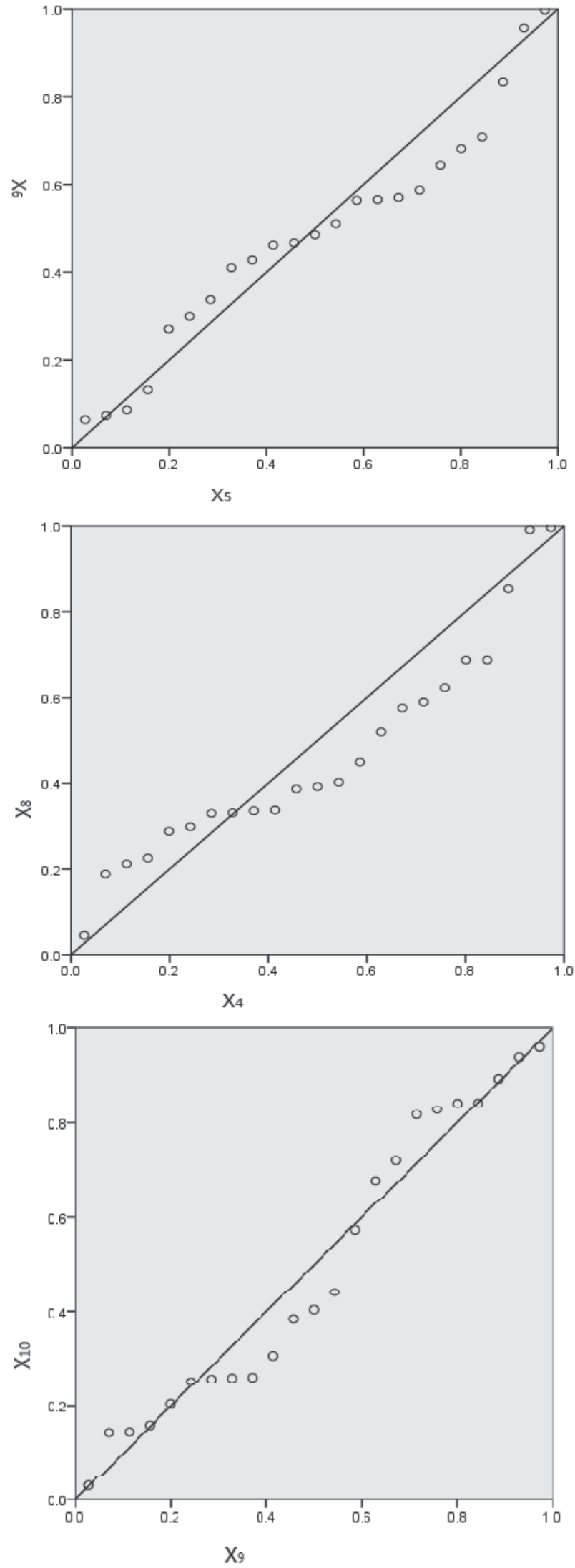

Fig. 2. The analysis diagram of correlation degrees between the $\mathrm{X}_{5}$ production value of the secondary industry and the $\mathrm{X}_{6}$ production value of the tertiary industry, between the $\mathrm{X}_{4}$ production value of the primary industry and $\mathrm{X}_{8}$ agricultural production value, as well as between $\mathrm{X}_{9}$ GDP and $\mathrm{X}_{10}$ fiscal revenue, respectively.

\section{Analysis of Driving Forces of LUCC}

Driving forces of land-use change include natural biological factors, socioeconomic factors, institutional factors, and technological factors [19]. According to different research approaches to driving forces, previous studies on driving forces can be divided into qualitative studies and quantitative ones, where the latter predominates. The driving forces can also be classified socially and naturally as a result of different driving factors, among which the social driving forces are a majority. Characteristics of a research area determine the way to choose corresponding analytical methods and driving factors [20]. The main driving force of landuse change with short turnover times is socioeconomic factors. The selection of driving factors is a prerequisite for relative analysis, and the driving model is the key. According to the idea and requirements of the principal component analysis, based on the present-day data conditions in Fuxian Lake watershed, the paper selected the 1990-2012 national economic statistics for Yuxi city in Yunnan Province as the background data, and picked the following 20 influential factors using the Delphi method: $X_{1}$ overall population, $X_{2}$ agricultural population (head), $X_{3}$ natural population growth rate (\%), $X_{4}$ the production value of primary industry $\left(10,000\right.$ yuan), $X_{5}$ the production value of secondary industry $(10,000$ yuan $), X_{6}$ the production value of tertiary industry (10,000 yuan), $X_{7}$ industrial production value (10,000 yuan), $X_{8}$ agricultural production value (10,000 yuan), $X_{9}$ GDP (10,000 yuan), $\mathrm{X}_{10}$ fiscal revenue $\left(10,000\right.$ yuan), $\mathrm{X}_{11}$ fiscal expenditure (10,000 yuan), $X_{12}$ rural income per capita (yuan), $X_{13}$ total retail sales of consumer goods (10,000 yuan), $X_{14}$ living expenditure per capita (yuan), $X_{15}$ grain total output $(10,000 \mathrm{~kg}), X_{16}$ the per unit area yield of grain $(\mathrm{kg}), X_{17}$ the amount of fertilizer used in agriculture (ton), $\mathrm{X}_{18}$ the amount of pesticide used in agriculture $(10,000 \mathrm{~kg}), \mathrm{X}_{19}$ annual average temperature $\left({ }^{\circ} \mathrm{C}\right), \mathrm{X}_{20}$ annual average precipitation $(\mathrm{mm})$, and $\mathrm{Y}$ cultivated area $(\mathrm{mu})$.

Through correlation coefficient matrix analysis of the selected 20 factors that impacted the land-use change in Fuxian catchment, the paper found that these factors are correlated with each other to different extents. There are 54 groups of factors with high correlation $(|r| \geq 0.9)$, where between $\mathrm{X}_{5}$ and $\mathrm{X}_{6}, \mathrm{X}_{4}$ and $\mathrm{X}_{8}$, and $\mathrm{X}_{9}$ and $\mathrm{X}_{10}$ there are relatively large correlations, with the corresponding correlation coefficient of 0.997 (Fig. 2).

The synthetic values of principal components, which could be computed by the principal component comprehensive model, were sequenced by size. This meant the comparison between independent comprehensive evaluations on various targeted areas. The ordering result was shown in Table 2 as follows.

\section{Analysis of the Driving Forces of LUCC in Fuxian Catchment}

According to the results of the above principal component analysis, among natural factors and human 
Table 2. the synthetic values of principal components.

\begin{tabular}{|c|c|c|c|c|c|c|}
\hline Factor & $F 1$ & Rank & F2 & Rank & F3 & Rank \\
\hline $\mathrm{X}_{1}$ & 0.817 & 12 & -0.513 & 19 & 0.063 & 6 \\
\hline $\mathrm{X}_{2}$ & 0.622 & 16 & -0.747 & 20 & 0.014 & 10 \\
\hline $\mathrm{X}_{3}$ & -0.887 & 20 & 0.330 & 3 & 0.131 & 5 \\
\hline $\mathrm{X}_{4}$ & 0.979 & 6 & 0.180 & 8 & 0.010 & 11 \\
\hline $\mathrm{X}_{5}$ & 0.974 & 9 & 0.204 & 5 & -0.019 & 16 \\
\hline $\mathrm{X}_{6}$ & 0.974 & 9 & 0.203 & 6 & -0.023 & 17 \\
\hline $\mathrm{X}_{7}$ & 0.984 & 5 & 0.110 & 11 & -0.048 & 19 \\
\hline $\mathrm{X}_{8}$ & 0.977 & 7 & 0.185 & 7 & 0.022 & 9 \\
\hline $\mathrm{X}_{9}$ & 0.994 & 1 & 0.046 & 13 & 0.007 & 12 \\
\hline $\mathrm{X}_{10}$ & 0.994 & 1 & 0.073 & 12 & 0.010 & 13 \\
\hline $\mathrm{X}_{11}$ & 0.964 & 11 & 0.234 & 4 & -0.039 & 18 \\
\hline $\mathrm{X}_{12}$ & 0.992 & 3 & 0.042 & 14 & 0.006 & 14 \\
\hline $\mathrm{X}_{13}$ & 0.773 & 13 & 0.486 & 1 & 0.047 & 7 \\
\hline $\mathrm{X}_{14}$ & 0.987 & 4 & 0.130 & 9 & 0.033 & 8 \\
\hline $\mathrm{X}_{15}$ & 0.382 & 18 & 0.334 & 2 & 0.694 & 1 \\
\hline $\mathrm{X}_{16}$ & 0.677 & 15 & -0.398 & 17 & 0.189 & 4 \\
\hline $\mathrm{X}_{17}$ & 0.460 & 17 & 0.113 & 10 & -0.663 & 20 \\
\hline $\mathrm{X}_{18}$ & 0.976 & 8 & -0.017 & 16 & -0.009 & 14 \\
\hline $\mathrm{X}_{19}$ & 0.726 & 14 & -0.398 & 18 & 0.245 & 3 \\
\hline $\mathrm{X}_{20}$ & -0.597 & 19 & 0.035 & 15 & 0.388 & 2 \\
\hline & & & & & & \\
\hline
\end{tabular}

factors predominantly, the paper selected the following representative factors that mainly influence LUCC in Fuxian watershed: $X_{1}$ overall population, $X_{2}$ agricultural population (head), $X_{3}$ natural population growth rate (\%), $\mathrm{X}_{4}$ the production value of primary industry (10,000 yuan), $\mathrm{X}_{5}$ the production value of secondary industry $(10,000$ yuan), $X_{6}$ the production value of tertiary industry $(10,000$ yuan), $X_{7}$ industrial production value (10,000 yuan), $X_{8}$ agricultural production value (10,000 yuan), $X_{9}$ GDP (10,000 yuan), $X_{10}$ fiscal revenue (10,000 yuan), $X_{11}$ fiscal expenditure (10,000 yuan), $X_{12}$ rural income per capita (yuan), $X_{13}$ total retail sales of consumer goods $(10,000$ yuan), $X_{14}$ living expenditure per capita (yuan), $X_{15}$ grain total output $(10,000 \mathrm{~kg}), X_{16}$ the per unit area yield of grain $(\mathrm{kg}), \mathrm{X}_{17}$ the amount of fertilizer used in agriculture (ton), $X_{18}$ the amount of pesticide used in agriculture $(10,000$ $\mathrm{kg}), \mathrm{X}_{19}$ annual average temperature $\left({ }^{\circ} \mathrm{C}\right), \mathrm{X}_{20}$ annual average precipitation $(\mathrm{mm})$, and $\mathrm{Y}$ cultivated area $(\mathrm{mu})$.

Using data from statistical yearbooks for Fuxian catchment and with the help of the SPSS software package, we obtained the multiple linear regression model between cultivated land in the land-use/land-cover watershed and their driving factors:

$\mathrm{Y}=-278415.849+4.369 \mathrm{X}_{1}-3.390 \mathrm{X}_{2}+23673.866 \mathrm{X}_{3}$ $+0.931 \mathrm{X}_{4}+0.966 \mathrm{X}_{6}+0.055 \mathrm{X}_{7}-1.258 \mathrm{X}_{8}+0.586 \mathrm{X}_{9}+$
$1.388 \mathrm{X}_{11}-160.638 \mathrm{X}_{12}-0.341 \mathrm{X}_{13}+64.143 \mathrm{X}_{14}-12.725 \mathrm{X}_{15}{ }^{-}$ $851.267 \mathrm{X}_{16}-0.683 \mathrm{X}_{17}-0.094 \mathrm{X}_{18}+32630.417 \mathrm{X}_{19}-$ $1382.148 \mathrm{X}_{20}$

...where $\mathrm{Y}$ denotes the cultivated area, and $\mathrm{X}_{1}-\mathrm{X}_{20}$ represent the aforementioned 20 factors.

In the model, $\mathrm{R}$ equaled 0.918 , and $\mathrm{R}^{2}$ was equal to 0.842 , which meant that the equation fit well; $F$ passed the test, with the test value of 1.187; and the coefficients of dependent variables also passed the test by large, whose test values were: $-0.438,1.516,-1.460,1.819,0.456$, $0.686,0.052,-0.694,1.133,1.804,-1.767,-1.427,0.800$, $-1.094,-0.443,-1.068,-0.410,1.650$, and -1.382 ; the model had been tested reliably, as its multicollinearity was up to the standard.

\section{Results and Analysis}

\section{LUCC in Fuxian Catchment for the Past four Decades}

In accordance with the remote sensing classification system, by use of ArcGIS, the extracted result of LUCC in Fuxian watershed underwent visualized integration and statistics (Fig. 3, Table 3). We calculated the rates for and the conversion matrix of areas of land-use/ land-cover types to vary with time, and obtained the corresponding temporal change as well as the relationship between different land-cover types during their mutual transformation (Fig. 4, Table 6).

According to Equation 2-1, the single dynamic degrees of various land-use categories in Fuxian catchment for the last 40 years could be obtained (Table 4). Equation 2-2 could be used to acquire the synthetic dynamic degree of different land-use types in the catchment for the last 40 years (Table 5). As can be seen from Table 2, there are generally greater land changes for roads, structures, artificial piling and digging land, and wastelands and bare surface from 1974 to 2014, as a comparison to the smaller changes of the rest of land types. The increase of areas happens on cropland, gardens, building regions (district), roads, structures, artificial piling and digging land, and wastelands and bare surfaces, while the area of water remains unchanged as a whole.

The land type with a positive dynamic degree has expanded in size, while the land type with a negative dynamic degree has shrunken. It is more precise if the absolute value of dynamic degrees per unit is used to measure the changing degree of land types. Through analysis of data in Table 4, it can be seen that the absolute value of dynamic degree for the area of cultivated land is higher during the period 1977-87 and 2000-06, with the respective values of $7.92 \%$ and $4.87 \%$; garden areas have been monitored since 2006 , and record great absolute values of dynamic degrees for all three monitoring periods; the area of woodland basically stay steady for different detection periods, except for a slightly larger dynamic degree from 2000 to 2006; the absolute values 


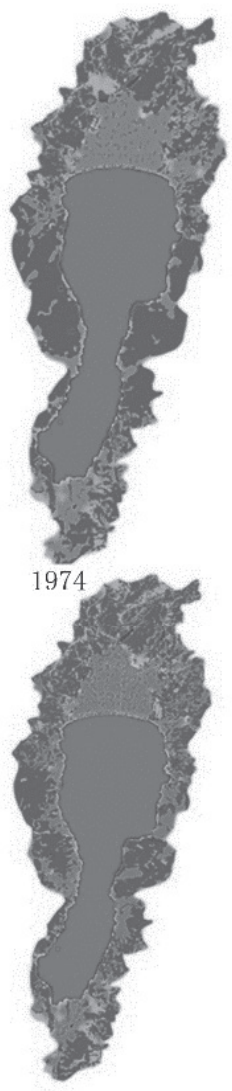

2000

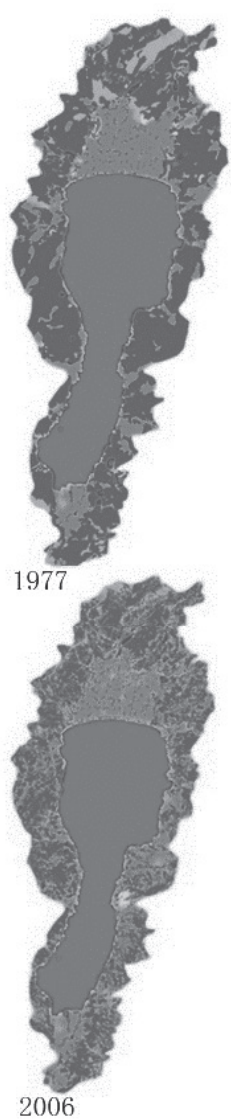

2006

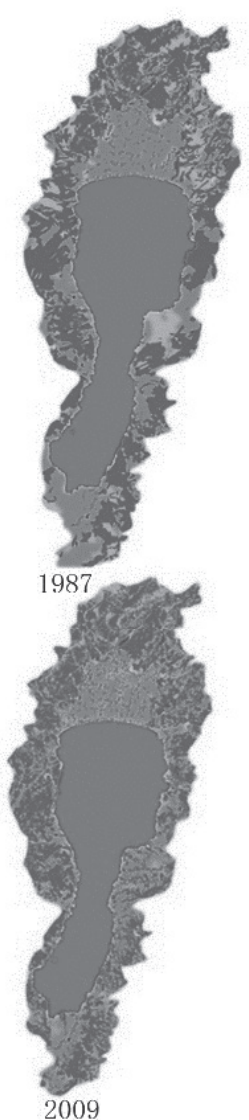

2009
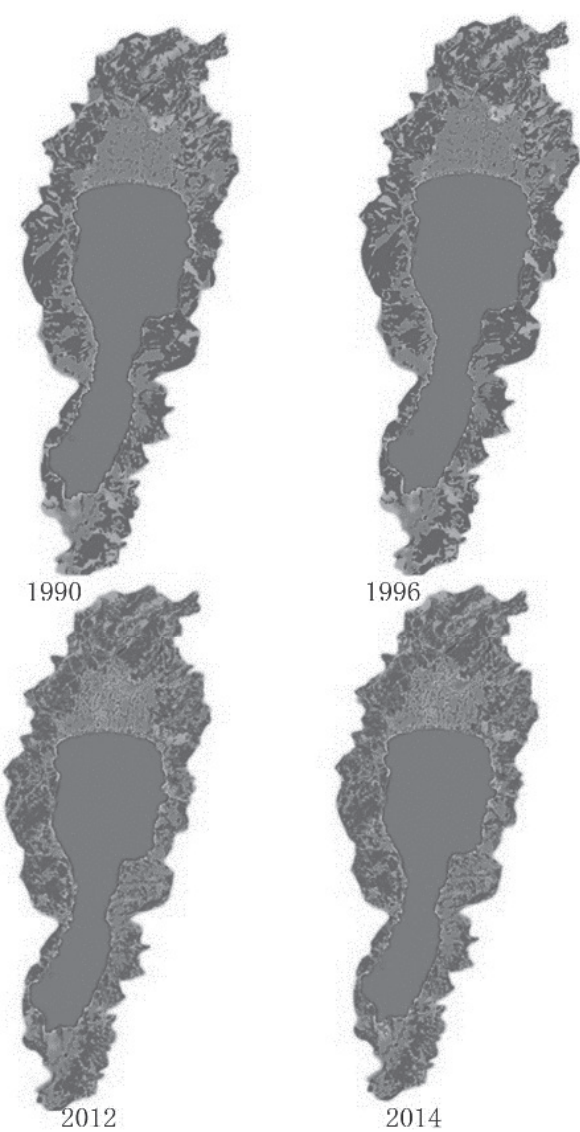

2014

Cultivated Land (CL) $\square$ Garden $(G)$

Woodland(WL)

Grass Land (GL)

Building Region(BR)

$\operatorname{Road}(\mathrm{R}) \square$ Structure(S)

Artificial Piling and Digging Land(APDL)

Water (W)

Desert and Bare surface(DB)

Fig. 3. Distribution map of various land-use/land-cover types in Fuxian Lake catchment, 1974 to 2014.

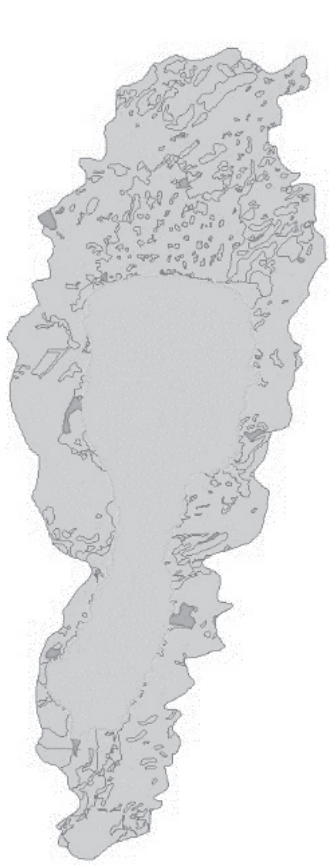

1974-1977

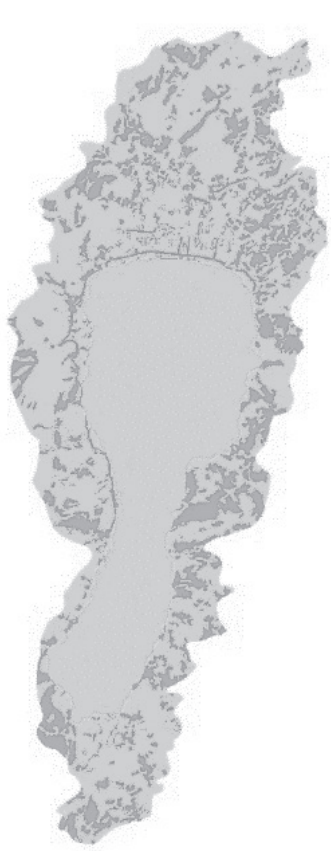

$1987-2000$
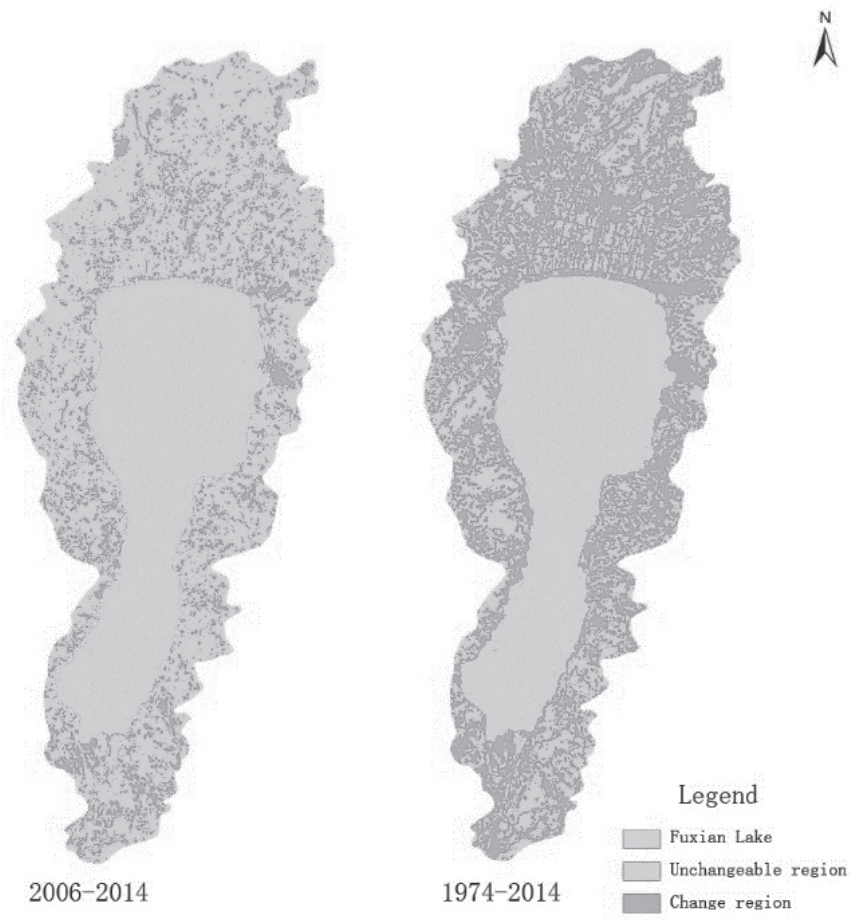

Fig. 4. Diagram of LUCC in Fuxian Lake catchment, 1974 to 2014. 
Table 3. Areas of various land-use/land-cover types in Fuxian Lake catchment, 1974 to 2014 (ha).

\begin{tabular}{|l|c|c|c|c|c|c|c|c|c|c|}
\hline $\begin{array}{l}\text { Year } \\
\text { type }\end{array}$ & 1974 & 1977 & 1987 & 1990 & 1996 & 2000 & 2006 & 2009 & 2012 & 2014 \\
\hline$(01)$ & $7,556.85$ & $7,717.40$ & $13,830.38$ & $13,944.29$ & $12,477.21$ & $12,225.08$ & $15,798.89$ & $15,355.33$ & $14,391.91$ & $13,840.46$ \\
\hline$(02)$ & $/$ & $/$ & $/$ & $/$ & $/$ & $/$ & 386.51 & 496.40 & 783.78 & 973.87 \\
\hline$(03)$ & $31,427.69$ & $31,221.07$ & $27,559.20$ & $27,397.42$ & $26,496.01$ & $25,392.99$ & $21,806.08$ & $21,947.51$ & $22,596.69$ & $22,472.71$ \\
\hline$(04)$ & $6,182.12$ & $6,216.23$ & $2,983.87$ & $3,041.31$ & $4,952.32$ & $6,307.94$ & $4,991.60$ & $4,924.57$ & $4,643.56$ & $4,940.17$ \\
\hline$(05)$ & 552.39 & 568.49 & $1,101.12$ & $1,105.28$ & $1,273.08$ & $1,287.13$ & $1,293.21$ & $1,368.25$ & $1,465.68$ & $1,486.01$ \\
\hline$(06)$ & $/$ & $/$ & 54.75 & 57.47 & 220.61 & 338.06 & 650.19 & 674.57 & 732.43 & 732.93 \\
\hline$(07)$ & $/$ & $/$ & $/$ & $/$ & $/$ & $/$ & 325.65 & 424.57 & 591.36 & 443.08 \\
\hline$(08)$ & $/$ & $/$ & $/$ & $/$ & $/$ & $/$ & 202.80 & 288.87 & 412.46 & 703.49 \\
\hline$(09)$ & $/$ & $/$ & 84.42 & 81.48 & 90.86 & 66.56 & 118.86 & 127.03 & 142.81 & 100.25 \\
\hline$(10)$ & $21,813.23$ & $21,809.07$ & $21,918.52$ & $21,905.03$ & $22,022.18$ & $21,914.50$ & $21,958.48$ & $21,925.16$ & $21,771.58$ & $21,839.30$ \\
\hline
\end{tabular}

Notes: "/" denotes that this land-cover type fails to extract due to restricted image resolution, and has nothing to do with the existence of this land-cover type in the research year - cultivated (1), gardens (2), woodland (3), grassland (4), building regions (district) (5), roads (6), structures (7), artificial piling and digging land (8), wastelands and bare surface (9), and water (10).

of dynamic degrees for grassland during 1977-87, 199096, 1996-2000, 2000-06, and 2012-14 reach 5.20\%, $10.47 \%, 6.84 \%, 3.48 \%$, and $3.19 \%$, respectively, and the absolute values of dynamic degrees for building regions (districts) during 1977-87, 1990-96, and 2009-12 are up to $9.37 \%, 2.53 \%$, and $2.37 \%$, respectively. For the three monitoring periods between 1990 and 2006, the dynamic degree of land use for roads changes remarkably. The land use dynamic degrees of structures and artificial piling and digging land, which was monitored after 2006, enjoy large change as well. There are high absolute values of dynamic degree for wastelands and bare surfaces during 19962000, 2000-06, 2009-12, and 2012-14, and the dynamic degree of water levels off during the 40-year monitoring period. In conclusion, the most active changes occur in gardens, woodlands, roads, structures, and artificial piling and digging land, while the rest of land-use categories remain basically unchanged.

In terms of synthetic land-use type, 1990-96 and 200006 have witnessed a larger change of dynamic degrees of $0.67 \%$ and $0.63 \%$, respectively; in contrast, the smaller change happens from 1974 to 1977 with a mere $0.16 \%$. The phenomenon shows that along with economic development, human activities have increasingly impacted land-use change.

Table 4. Single dynamic degrees of various land-use types in Fuxian Lake catchment for the last 40 years (\%).

\begin{tabular}{|c|c|c|c|c|c|c|c|c|c|c|}
\hline period & 1974 & 1977 & 1987 & 1990 & 1996 & 2000 & 2006 & 2009 & 2012 & 1974 \\
\hline Type & -77 & -87 & -90 & -96 & -2000 & -06 & -09 & -12 & -14 & -2014 \\
\hline$(01)$ & 0.71 & 7.92 & 0.27 & -1.75 & -0.51 & 4.87 & -0.94 & -2.09 & -1.92 & 2.08 \\
\hline$(02)$ & 1 & I & 1 & I & / & I & 9.48 & 19.30 & 12.13 & I \\
\hline (03) & -0.22 & -1.17 & -0.20 & -0.55 & -1.04 & -2.35 & 0.22 & 0.99 & -0.27 & -0.71 \\
\hline (04) & 0.18 & -5.20 & 0.64 & 10.47 & 6.84 & -3.48 & -0.45 & -1.90 & 3.19 & -0.50 \\
\hline$(05)$ & 0.97 & 9.37 & 0.13 & 2.53 & 0.28 & 0.08 & 1.93 & 2.37 & 0.69 & 4.23 \\
\hline (06) & 1 & 1 & 1.66 & 47.31 & 13.31 & 15.39 & 1.25 & 2.86 & 0.03 & 1 \\
\hline (07) & 1 & 1 & 1 & 1 & 1 & I & 10.13 & 13.09 & -12.54 & 1 \\
\hline (08) & 1 & 1 & 1 & 1 & 1 & 1 & 14.15 & 14.26 & 35.28 & 1 \\
\hline (09) & 1 & 1 & -1.16 & 1.92 & -6.69 & 13.10 & 2.29 & 4.14 & -14.90 & 1 \\
\hline (10) & -0.01 & 0.05 & -0.02 & 0.09 & -0.12 & 0.03 & -0.05 & -0.23 & 0.16 & 0.00 \\
\hline
\end{tabular}

Note: "/ denotes that the dynamic change degree of this land-cover type fails to be accurately computed due to different image resolutions. 
Table 5. Synthetic dynamic degree of land-use types in Fuxian Lake catchment over the last 40 years.

\begin{tabular}{|c|c|c|c|c|}
\hline period & 1974- & 1987- & $2006-$ & 1974- \\
\hline Land-use type & 77 & 2000 & 14 & 2014 \\
\hline LC & $0.16 \%$ & $0.67 \%$ & $0.63 \%$ & $0.39 \%$ \\
\hline
\end{tabular}

\section{The Conversion Matrix of LUCC in Fuxian Lake Watershed}

Based on the land-use/land-cover maps for Fuxian Lake watershed, we can compute the corresponding conversion matrix of land use from 1974 to 2014 (Table 6).

During 1974-2014, the cultivated land in the watershed was converted to various types ranging from grassland, woodland, gardens, and building regions to roads, where the conversion to woodland occupies a large proportion. The area of conversion from woodland to cultivated land exceeds that of the opposite direction; in addition, part of woodland is shifted into grassland, and these two phenomena caused a decrease in woodland area. A great deal of former grassland has turned into either woodland or cultivated land. Despite an increasing trend, the small proportion of the area of building regions (districts) in the whole watershed renders the corresponding conversion rate small; only part of the building regions (districts) change into cultivated land. The area of water remains unchanged, by and large, except that a grain of water has been transformed into other types. Therefore, it can be seen that over the 40-year period, the major land-use change types are arable land, woodland, and grassland -all of which have a relatively large conversion proportion.

\section{Spatiotemporal Change of Various LUCC Types in Fuxian Lake Catchment}

Through a comparison between the changes of landcover types in Fuxian catchment for the last 40 years we can obtain a diagram of the changing trend of areas of different land-cover types (Fig. 5).
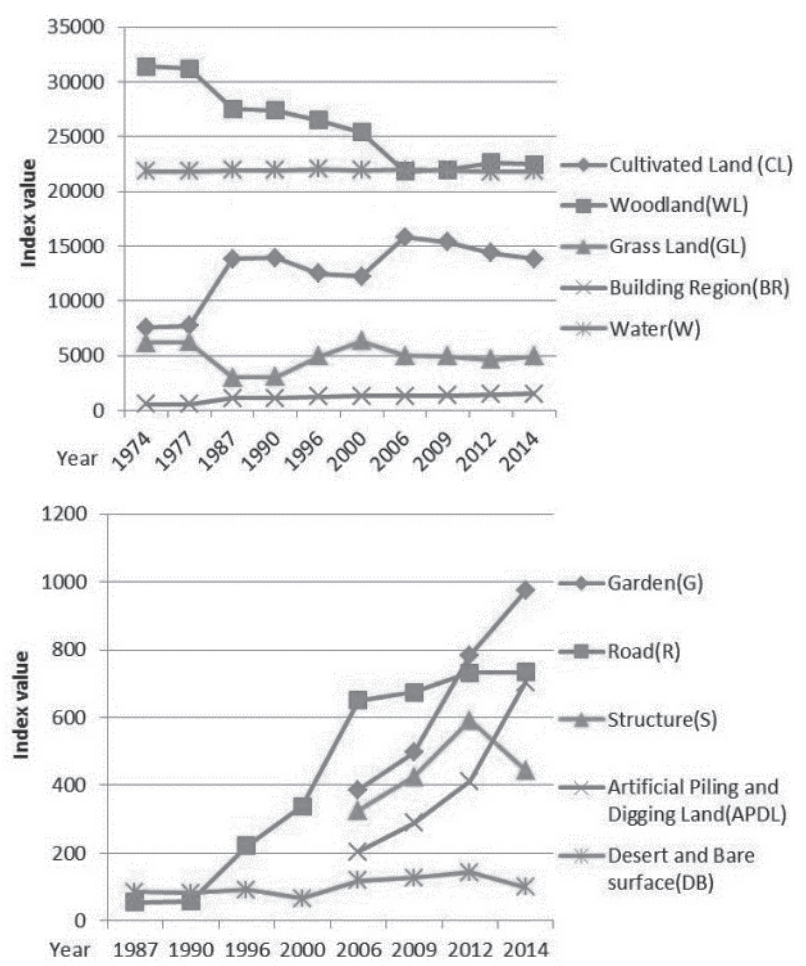

Fig. 5. Diagram of the changing trend of areas of different landcover types.

As can be seen, from 1974 to 2014 there are areas rising up for gardens, building regions (districts), roads, structures, and artificial piling and digging land, in that the significantly increasing human activities due to economic growth promote the development of these landuse types readily linked to human economic activities. The area of cultivated land has a climbing trend before the year 2000, and gradually falls after 2000, to be mainly replaced by forests and grasslands; the area of woodland presents a noteworthy trend of decrease, which proves the great human-induced damage to woodland; after 2006, with the implementation of the policy of converting degraded farmland into forest, the area of woodland sees a tendency of gain rather than declination, and the change of grassland areas is small, mainly due to natural succession, conversion of degraded land for farming into

Table 6. Conversion matrix of land use in Fuxian Lake watershed from 1974 to 2014 (ha).

\begin{tabular}{|c|c|c|c|c|c|c|c|c|c|c|c|}
\hline 2014 & \multirow[t]{2}{*}{ (01) } & \multirow[t]{2}{*}{ (02) } & \multirow[t]{2}{*}{ (03) } & \multirow[t]{2}{*}{ (04) } & \multirow[t]{2}{*}{ (05) } & \multirow[t]{2}{*}{ (06) } & \multirow[t]{2}{*}{ (07) } & \multirow[t]{2}{*}{ (08) } & \multirow[t]{2}{*}{ (09) } & \multirow[t]{2}{*}{ (10) } & \multirow[t]{2}{*}{$\begin{array}{l}\text { Total } \\
\text { value }\end{array}$} \\
\hline 1974 & & & & & & & & & & & \\
\hline (01) & $4,600.60$ & 229.89 & $1,022.96$ & 240.92 & 700.26 & 305.45 & 247.26 & 112.95 & 18.62 & 77.94 & $7,556.85$ \\
\hline (03) & $7,252.81$ & 579.43 & $18,761.12$ & $3,410.34$ & 384.86 & 324.92 & 124.75 & 435.20 & 51.23 & 103.03 & $31,427.68$ \\
\hline (04) & $1,816.59$ & 146.93 & $2,611.23$ & $1,226.62$ & 84.27 & 74.72 & 46.57 & 152.43 & 6.19 & 16.57 & $6,182.12$ \\
\hline$(05)$ & 157.28 & 9.65 & 24.15 & 10.22 & 311.43 & 21.23 & 13.46 & 1.84 & 0.23 & 2.90 & 552.39 \\
\hline (10) & 13.19 & 7.97 & 53.26 & 52.06 & 5.19 & 6.60 & 11.04 & 1.07 & 23.98 & $21,638.86$ & $21,813.23$ \\
\hline$\square \square$ & $13,840.46$ & 973.87 & $22,472.71$ & $4,940.17$ & $1,486.01$ & 732.93 & 443.08 & 703.49 & 100.25 & $21,839.30$ & $67,532.27$ \\
\hline
\end{tabular}


grasses, and sowing by hand. The area of wastelands and bare surface has witnessed an opposite trend of decrease year by year, which indicates that through afforestation and other economic activities, the undeveloped land has been cultivated. The area of water remains essentially unchanged.

\section{Driving Factors of LUCC in Fuxian Lake Catchment}

According to the regression equation, it can be seen that the cultivated area in Fuxian watershed is positively correlated with such factors as overall population, natural population growth rate, the production value of primary industry, the production value of tertiary industry, industrial production value, GDP, fiscal expenditure, living expenditure per capita, and annual average temperature, and it is negatively correlated with some other factors, including agricultural population, agricultural production value, rural income per capita, total retail sales of consumer goods, grain total output, the per unit area yield of grain, the amount of fertilizer used in agriculture, the amount of pesticide used in agriculture, and annual average precipitation.

\section{Discussions}

RS technology and GIS technology are used together to study the characteristics and driving forces of land-use change in Fuxian watershed. In this way, the contradiction between land use for ecologically fragile regions in plateau or near lakes and social development can be mitigated, and the relationship between human beings and lands at the regional scale can be coordinated. The research result provides data support for rational control and regulation on man-earth systems, and is of great scientific significance to regional ecological safety and sustainable development. The magnitude and structure of land use, if changed greatly, will incur an array of regional-level eco-environmental problems. In this connection, future research should focus on land-use change mechanism, the change trend of cultivated land in Fuxian watershed, and how ecological environment responds to it. Meanwhile, a practical scheme for ensuring Fuxian Lake sustainability must include using high-resolution images to monitor land-use change four times in a year in the watershed. Future studies should consider policy factors to describe and quantify in spatial dimension the LUCC driving forces procession.

\section{Conclusions}

Over the last 40 years, the land-use conditions in Fuxian Lake catchment have been influenced to a certain degree by more frequent human activities, economic development, and the optimized and adjusted industrial structures. The areas of building regions (districts), roads, structures, artificial piling and digging land, wastelands and bare surface, and gardens have been noticeably enlarged, while there is a downward tendency for the areas of cultivated land, grassland, woodland, and water. Fuxian watershed has witnessed degraded grassland and woodland as well as collapsing vegetation cover areas until their number starts to level off after 2006, when the policy of converting degraded cultivated land to forests (grassland) was carried into effect. This phenomenon reflects the improved land ecological environments and that the expansion of cultivated land has slowed as a response to the 2006 policy. However, as a result of infrastructure construction, the areas of building regions (districts), roads, and other land-use types that are closely linked to human lives are still expanding. The change of water areas is affected by climates and humanities on the one hand, and by several years of constant drought in Yunnan Province as well as the acceleration of urbanization in the area on the other.

The change of land-use in the watershed was predominantly driven by socioeconomic factors, including overall population, natural population growth rate, the production value of primary industry, and the production value of tertiary industry.

\section{Acknowledgments}

The authors are grateful to the editor and anonymous referees' reviews for their valuable comments and helpful suggestions. In addition, this work is supported by the National Natural Science Foundation of P.R. China (grant Nos. 41661086, 41561086, 41561048, and 41461038); the Yunnan Provincial Science and Technology Program (grant No. 2008PY056); the National Geographical State Monitoring Demonstrative Project, "Dynamic monitoring for ecological environment in Fuxian lake watershed," from the National Administration of Surveying, Mapping, and Geoinformation (file No. 201435); and the nonprofit Industry Financial Program of Surveying and Mapping, geo-information as "Monitoring technologies for important geographical elements of Silk Road Economic Belt and their application demonstration" (grant No. 201512027).

\section{References}

1. LIU J.Y., ZHANG Z.X., ZHUANG D.F., WANG Y.M., ZHOU W.C., ZHANG S.W., LI R.D., JIANG N., WU S.X. A study on the spatial-temporal dynamic changes of landuse and driving forces analyses of China in the 1990s. Geographical Research, 22 (1), 1, 2003.

2. LIU J.Y., ZHANG Z.X., XU X.L., KUANG W.H., ZHOU W.C., ZHANG S.W., LI R.D., YAN C.Z., YU D.S., WU S.X., J IANG N. Spatial Patterns and Driving Force of Land Use Change in China in the Early 21 Century. Acta Geographica Sinica, 64 (12), 1411, 2009.

3. TURNER B.L., LAMBIN E.F., REENBERG A. The emergence of land change science for global environmental change and sustainability. PNAS, 104 (52), 20666, 2007. 
4. WASIGE J.E., GROEN T.A., SMALING E., JETTEN V. Monitoring basin-scale land cover changes in Kagera Basin of Lake Victoria using ancillary data and remote sensing. International Journal of Applied Earth Observation and Geoinformation, 21, 32, 2013.

5. SKOLE D., TUCKER C. Tropical deforestation and habitat fragmentation in the Amazon: satellite data from 1978-1988. Science, 260, 1905, 1993.

6. OJIMA D.S., GALVIN K.A., TURNER B.L. II. The global impact of land-use change. BioScience, 44 (5), 300, 1994.

7. FISCHER G., SUN L.X. Model based analysis of future land-use development in China. Agriculture,Ecosystems \&Environment, $85(1 / 2 / 3), 163,2001$.

8. OTSUBO K. Land use for global environmental conservation (LU/GEC): final report of the LU/GEC first phase: 19951997. Tokyo: National Institute for Environmental Studies, Environmental Agency of Japan, 1999.

9. LIU G.Z., ZHEN J.H., LIU G.H., LI H.Y., LIU Z.R., XI J.R. Analysis of land usage variations and driving forces in the area around Xanadu Relics. Pratacultural Science, 32(8), 1363, 2015.

10. SUN Y.H., GUO T., CUI X.M. Intensity analysis and stationarity of land use change in Kunming City. Progress in Geography, 35 (2), 245, 2016.

11. WU K., WANG W.J.,LIU J.H., ZHANG Z., HU S.W. Analysis on Characteristics and Driving Force of Land Use Change in Chengdu - Chongqing Economic Zone. Journal of Environmental Engineering Technology, 5 (1), 29, 2015.

12. LI J.L., JIANG L.L., BAO, A., CHANG C., BAI J., LIU H.L. Spatio-temporal change analysis of cultivated land in Manas drainage basin during 1962-2010. Transactions of the
Chinese Society of Agricultural Engineering (Transactions of the CSAE), 31 (4), 277, 2015.

13. PENG F., WENG Q.H. A time series analysis of urbanization induced land use and land cover change and its impact on land surface temperature with Landsat imagery. Remote Sensing of Environment, 175, 205, 2016.

14. WANG S.M., DOU H.S. The Blog of China Lake. Beijing: Science Press. 374, 1998.

15. GAO W.,CHEN Y., XU M.,GUO H., XIE Y. Trend and driving factors of water quality change in Lake Fuxian (1980-2011). Journal of Lake Science, 25 ( 5), 635, 2013.

16. First National Geographic National Census Leading Group Office of the State Council. First National Census geography training materials 2-Geography Census contents and index. Beijing: Surveying and Mapping Press, 2013.

17. HAN H.Q., YANG G.B., ZHANG F.T. Spatio-temporal analysis of land use changes in Guizhou Province based on landform characteristics.Journal of Nanjing Forestry University:Natural Sciences Edition, 39 (5), 99, 2015.

18. YANG J., WANG C.Q., XIA J.G. Spatial planning o land use based on celluar automata modeling: A case study of Dongpo District, Meishan City Acta Pedologica Sinica, 47 (5), 847, 2010

19. YANG M., GHANG G.L.,HOU Y.P. Advances and Prospects of the Driving Force of Regional Land Use Change Researches.Geography and Geo-InformationScience, 27 (1), 95, 2011.

20. QIN F., ZHOU J.,LIU J., ZHANG L.G., GAO L. Land use change dynamics and driving forces in Duolun County, Inner Mongolia. Journal of Arid Land Resources and Environment, 30 (6), 31, 2016. 
